\title{
Control of local immunity by airway epithelial cells
}

\author{
M Weitnauer ${ }^{1}$, V Mijošek ${ }^{1}$ and AH Dalpke ${ }^{1,2}$
}

The lung is ventilated by thousand liters of air per day. Inevitably, the respiratory system comes into contact with airborne microbial compounds, most of them harmless contaminants. Airway epithelial cells are known to have innate sensor functions, thus being able to detect microbial danger. To avoid chronic inflammation, the pulmonary system has developed specific means to control local immune responses. Even though airway epithelial cells can act as proinflammatory promoters, we propose that under homeostatic conditions airway epithelial cells are important modulators of immune responses in the lung. In this review, we discuss epithelial cell regulatory functions that control reactivity of professional immune cells within the microenvironment of the airways and how these mechanisms are altered in pulmonary diseases. Regulation by epithelial cells can be divided into two mechanisms: (1) mediators regulate epithelial cells' innate sensitivity in cis and (2) factors are produced that limit reactivity of immune cells in trans.

\section{INTRODUCTION}

Airway epithelial cells: beyond the barrier function

The simplified equation of cellular or aerobic respiration is $\mathrm{C}_{6} \mathrm{H}_{12} \mathrm{O}_{6}+6 \mathrm{O}_{2} \rightarrow 6 \mathrm{CO}_{2}+6 \mathrm{H}_{2} \mathrm{O}$. The vital consequence of this equation is that multicellular organisms, such as mammals, need a specialized organ to facilitate gas exchange between blood and air. In mammals, this is achieved by the lung, an organ of the respiratory system. The latter can be divided into the conducting airways (consisting of the upper respiratory tract, trachea, and bronchi) and the respiratory part (consisting mainly of alveoli). The lung must be actively ventilated to satisfy the amount of air needed. Therefore, 10-20,000 l of air per day is ventilated over the roughly $100 \mathrm{~m}^{2}$ surface of the lung. Thus, the lung is by far the largest organ of the human body with direct contact to the atmospheric environment, and, therefore, is prone to infectious attack. Moreover, to facilitate effective gas exchange, the membrane separating blood from inhaled air is only $1-2 \mu \mathrm{m}$ thick. Thus, the interior of the human body is separated from the environment by a tennis court-sized surface, which has a thickness of roughly $1 / 10$ th the diameter of the cell nucleus. This makes the lung an attractive entry gate for pathogens. To prevent infection, the lung is equipped with several defense mechanisms; specialized cells of the immune system including alveolar macrophages and dendritic cells are able to sense and kill pathogens and to mount a protective inflammatory response. ${ }^{1}$
For decades, the perception of epithelial cell function has mainly been to build up a physical barrier to limit entry and to foster removal of pathogens. However, it has become clear that airway epithelial cells have a much more active role in the initiation of immune reactions. Besides the expression of pattern recognition receptors (PRRs) on professional immune cells (alveolar macrophages, sub- or intraepithelial dendritic cells), airway epithelial cells have also been shown to express Toll-like receptors, ${ }^{2}$ RIG-I, ${ }^{3}$ C-type lectins, ${ }^{4,5}$ and inflammasome components. ${ }^{6-8}$ So far, the relevance of the recently discovered cyclic GMP-AMP synthase in respiratory epithelial cells ${ }^{9}$ remains unclear. The specific PRR/pathogen-associated molecular pattern (PAMP) combinations relevant for detection of certain pathogens have been comprehensively reviewed previously. ${ }^{10}$ Thus, epithelial cells are equipped to participate in innate detection of microbial encounter.

\section{Epithelial cells induce an airway-specific immune microenvironment}

Air does not only contain potential pathogens but is also contaminated with organic or inorganic material, e.g., microbial cell wall constituents such as lipopolysaccharide (LPS). These substances will be sensed by PRRs expressed by airway epithelial cells, and have been demonstrated to be sufficient to induce an inflammatory response if systemically applied. ${ }^{11,12}$ Obviously, if the same were true for the respiratory system this

${ }^{1}$ Department of Infectious Diseases, Medical Microbiology and Hygiene, University Hospital Heidelberg, Heidelberg, Germany and ${ }^{2}$ Translational Lung Research Center (TLRC), Member of the German Center for Lung Research (DZL), Heidelberg, Germany. Correspondence: AH Dalpke (alexander.dalpke@med.uni-heidelberg.de) 
would lead to frequent, if not chronic, inflammation of the fragile respiratory tissue towards harmless, low-dose microbial pollutants. As inflammation inevitably induces some degree of collateral damage, this would eventually lead to a destruction of the fragile pulmonary system.

We therefore propose that mechanisms in the respiratory system have evolved to keep immune functions under control. This hypothesis follows the concept of specific immune microenvironments that shape and adjust local immune responses to organ-specific needs. ${ }^{13}$ Obviously, microenvironmentspecific cells must exert those regulatory effects on professional immune cells. Thus, airway epithelial cells, the first cells to make contact with inhaled microbial products or antigens, not only behave as innate immune sensors but also as immune modulators in parallel. The modulatory function is of specific importance during homeostasis, whereas the sensor function is needed in case of true microbial threat. Indeed, airway epithelial cells have been demonstrated to control local innate and adaptive immune responses, thereby keeping potentially damaging immune responses under control. We suggest that under homeostatic conditions, an important function of airway epithelial cells is to modulate the sensitivity of innate immune sensing. Various regulatory cascades and mediators have been shown to be involved in this process. Upon challenge with antigens or pathogens exceeding a certain threshold of tolerance, this inhibitory microenvironment might switch to a stimulatory one that now contributes to the initiation of immune responses. A logical consequence of such a concept is that spontaneous loss of these modulatory factors might be involved in the development of chronic airway diseases. Specific factors involved in this regulatory network and how these factors are modulated under various diseased conditions are the matter of this review. We will mostly focus on airway epithelial cells, but some of the regulatory mechanisms have also been shown to occur at the alveolar level. Whether differences in regulatory circuits based on the anatomical hierarchy of epithelial cells in the lung exist is not known in detail.

Under homeostatic conditions, control of professional immune cells' reactivity in the microenvironment of the airways can mechanistically be divided into two strategies. On the one hand, epithelial cell-derived mediators or intrinsic properties regulate sensitivity and reactivity of lower respiratory tract epithelial cells themselves (autocrine or cis-acting factors). On the other hand, epithelial cells produce factors that act on local immune cells including dendritic cells, macrophages, and lymphocytes (paracrine or trans-acting factors) (Figure 1).

\section{CIS-ACTING FACTORS REGULATING AIRWAY EPITHELIAL CELLS' SENSING FUNCTION}

Supported by various experimental observations, we suggest that epithelial cells under homeostatic conditions are hyporesponsive towards microbial stimulation, thereby adjusting the "reaction" threshold to the local microbial burden. The default setting of airway epithelial cells is "hyporesponsive" towards proinflammatory products, and this can be achieved by regulating epithelial-intrinsic mechanisms.

\section{Organization of the epithelial barrier}

The epithelium of the lower respiratory tract is built up by several different cell types, varying in the composition from proximal to distal. The main airway cell types forming the pseudostratified epithelium in the conducting airways are ciliated epithelial cells, non-ciliated mucous goblet cells, club cells (originally known as clara cells), and undifferentiated basal cells. The alveolar epithelium consists only of type I and type II alveolar cells. The mucus layer and the physical barrier formed by the epithelium contribute to a first line of defense. In consequence, epithelial cells are physically separated from potential stimulatory factors by mucus, a mechanism that also clears the lung from potentially activating compounds (mucociliary clearance (MCC) system), or surfactant, which gets eventually cleared by phagocytosis of alveolar macrophages. ${ }^{14,15}$ Moreover, the physical barrier produced by the epithelium itself separates potential proinflammatory signals from (reactive) interstitial macrophages, dendritic cells, and lymphocytes. Originally, this protective barrier has been shown in the intestine for the gut microbiota. As this effect is mediated by the secretion of anti-microbial peptides and the airway epithelium is also able to produce similar factors, a protective barrier can be expected to be operative in the lung. ${ }^{16-18}$

\section{Epithelial cells separate microbial products from the body's interior, thus limiting microbial access to immune sensors}

An important function ${ }^{19}$ of epithelial cells is to act as a physical barrier towards the outer environment. Transcellular junctions are formed by apical tight junctions, adherens junctions, and desmosomes. Tight intercellular connections are important not only to prevent paracellular transport of ions, water, or cells into the airway lumen but also to physically separate microbial compounds from professional immune cells. Tight junctions limit access of airborne substances to the body interior. Professional luminal antigen sampling thus requires specific mechanisms, and indeed, it has been demonstrated that $\mathrm{CD}_{103}{ }^{+}$intraepithelial dendritic cells are able to stretch cellular extensions into the airway lumen, bypassing this barrier. ${ }^{20-22}$ Even though alveolar macrophages are found at the luminal side in the alveolar space, these cells do not get direct access to pathogens because of a layer of surfactant. Moreover, they reside in the most distal part of the lung system and are therefore situated behind the filtration barrier of the upper or conducting airways. The presence of macrophages in the lumen also results in a spatial segregation allowing localized, restricted defense reactions without directly inducing a system-wide response. Additionally, cells sampling luminal content are educated by various paracrine-acting factors derived from epithelial cells further discussed below.

The importance of a functional tight epithelial barrier is demonstrated in the context of acute respiratory distress syndrome. Even though this disease is primarily driven by a loss of endothelial barrier integrity, full-blown disease develops only 
if the epithelial barrier is impaired in parallel. ${ }^{23,24}$ Loss of epithelial cell integrity allows neutrophils to get in contact with luminal bacterial products. This leads to the release of reactive oxygen species and other factors (e.g., neutrophilic elastase), which further exacerbate the disease. Moreover, several studies demonstrated impaired epithelial barrier function in asthmatic patients, and increased shedding of epithelial cells, impairing the barrier function, has also been suggested. ${ }^{25,26}$

\section{Mucus as a defense layer limiting access to antigens and microbes}

To strengthen the physical barrier, goblet cells are interspersed in the airway epithelial layer or in the submucosal glands. They secrete mucins into the airway lumen to build up a protective layer of mucus. Mucins are high-molecular-weight glycoproteins, of which at least 16 have been identified to be expressed in the lung (MUC1, MUC2, MUC4, MUC5AC, MUC5B, MUC7, MUC8, MUC11, MUC13, MUC15, MUC16, MUC18, MUC19, MUC20, MUC21, and MUC22). ${ }^{27}$ Interestingly, not only goblet cells produce mucins but also club cells (MUC5AC $)^{28}$ and alveolar epithelial cells (MUC1). ${ }^{29}$ Mucins are heavily post-translationally modified and extremely hydrophilic. Their main function is to form a protective mucus barrier to trap inhaled particles, which are subsequently actively transported out of the respiratory tract by MCC. Moreover, mucins also display anti-microbial, antiprotease, and antioxidant activities, ${ }^{27}$ thereby contributing to unspecific, innate immune defense. Failure in the MCC leads to the accumulation of mucus in the lung, resulting in chronic airway inflammation, as seen in patients with chronic obstructive pulmonary disease (COPD), cystic fibrosis (CF), or primary ciliary dyskinesia. ${ }^{30}$ Coordinated beating of cilia requires intense cell-cell communication via connexins, exemplifying the importance of an intact epithelial cell layer. Seven airway mucins (MUC2, MUC5AC, MUC5B, MUC6, MUC7, MUC8, and MUC19) are considered to be secreted into the airway lumen, whereas the others remain membrane-tethered on the apical side of the epithelium. ${ }^{27}$ The gel-like mucus, built by the secreted mucins, floats atop an apical periciliary liquid layer, also known as airway surface layer. The properties of this layer are important for effective MCC and are determined, on the one hand, by ions and other small molecules secreted, on the other hand, by epithelial cells, but most importantly by membrane-tethered mucins, especially MUC1, MUC4, and MUC16. ${ }^{31}$ MUC5AC and MUC5B are the most abundantly secreted mucins in the conducting airways. Even though the exact role of these two mucins in regulating the airway immune system is unknown, it has been reported that MUC5AC is inducible under inflammatory condition, while MUC5B is constitutively expressed. ${ }^{32,33}$ The relative importance of MUC5B compared with MUC5AC in homeostatic non-diseased conditions is reflected by the phenotypes of the respective knock-out mice. Muc5ac-deficient mice are viable and do not display any respiratory disease symptoms. However, these mice fail to recruit neutrophils in response to an acute challenge with Trichuris muris or in acute lung injury. ${ }^{34,35}$ In contrast, Muc5b-deficient mice spontaneously develop severe pulmonary pathology, mucus obstruction, and chronic bacterial infection. ${ }^{36}$ Most likely, this is due to the inability to clear particles or pathogens along with a decrease in interleukin-23 (IL-23) production by macrophages or dendritic cells. ${ }^{36}$ Mucus production and mucus transport, therefore, limit contact between airway epithelial cells and immunostimulatory substances. This is especially true for particles having an aerodynamic diameter larger than $2-3 \mu \mathrm{m}$, which are prone to precipitate after inhalation in the conducting airways. ${ }^{37}$

An important immunomodulatory mucin is MUC1, expressed not only in goblet cells but also in lymphocytes and dendritic cells. After secretion, it remains tethered to the cell membrane, where it can be released by neutrophilic elastase. Exemplifying its modulatory function, it has been shown that Mucl is a receptor for Pseudomonas aeruginosa, an opportunistic lung pathogen. Muc1-deficient mice displayed better lung clearance of $P$. aeruginosa compared with wild-type littermate. ${ }^{38}$ This was accompanied by increased tumor necrosis factor- $\alpha$ (TNF $\alpha)$ and KC levels in the bronchoalveolar lavage liquid, resulting in elevated numbers of neutrophils and clearance of $P$. aeruginosa. As $P$. aeruginosa is mainly recognized by epithelial Toll-like receptor 5 (TLR5)/flagellin, this observation was interpreted as an indication that Mucl has an inhibitory function on epithelial TLR5 signaling. ${ }^{39}$

\section{Epithelial cell-intrinsic microbial hyporesponsiveness}

An increasing number of reports now indicate that TLR signaling is actively suppressed in the airway and also in alveolar epithelial cells under homeostatic, non-stressed conditions. This hyporesponsiveness of airway cells has been observed for TLR2 and TLR4 agonists. ${ }^{2,40-42}$ Even though these cells express TLR2 and TLR4, direct stimulation with Gram-positive bacteria or LPS does not result in a strong induction of proinflammatory cytokines. It has been postulated that the lack of expression of CD36, a cofactor of TLR2, as well as MD2 and CD14, cofactors of TLR4, are responsible for this hyporesponsiveness. ${ }^{2,41,42}$ Regulation of coreceptors might be an organ-specific mean to adjust the sensor threshold (of various innate immune receptors) to the specific needs of a given compartment.

Similar observations have been made for alveolar epithelial cells. Even though they express TLR2 and TLR4, alveolar type II (AT-II) cells in contrast to alveolar type I (AT-I) cells seem to be hyporesponsive towards LTA and LPS and act anti-inflammatory. ${ }^{43}$ This tolerance is partially mediated by an epigenetic mechanism induced by repeated challenge of these cells with LPS or LTA ${ }^{44}$ (reflecting a phenomenon known as endotoxin tolerance). In addition, surfactant produced by AT-II cells can also have anti-inflammatory properties. Especially SP-A and SP-D, two of four surfactant proteins (SP), and phosphatidyl glycerol-containing surfactant vesicles are able to bind directly to TLR2, TLR4, MD2, and CD14, thereby blocking the interaction of PAMPs with these receptors. ${ }^{45-48}$ Similarly, SP-C has also been shown to bind 
LPS, thereby scavenging potential harmful LPS in the alveoli. Interestingly, LPS and other proinflammatory cytokines are able to suppress SP expression in a dose-dependent manner in AT-II cells. ${ }^{49}$ This indicates that the initial levels of SP present in the alveoli dictate a threshold for sensing LPS, which must be overcome to reduce the anti-inflammatory properties of SP on alveolar macrophages and AT-I cells. Once this threshold is exceeded, LPS and proinflammatory cytokines are able to suppress further SP expression and potentiate inflammation ${ }^{49}$ (feedforward amplification). The threshold needed to overcome this inhibition can be achieved not only by a single bolus dose but could also accumulate over time because of disturbances in the clearance of the lung. ${ }^{36}$

Epithelial tight junctions result in polarization of airway cells. Restriction of sensor molecules to the inaccessible basolateral side has been suggested as another mechanism contributing to reduce PRR sensing of surface-borne stimulation. Thus, TLR4 is less expressed at the apical side. ${ }^{40,50}$ Only virulent pathogens, overcoming the physical barrier, could access the sensor molecules, indicating true and present danger within this compartment. ${ }^{40}$ Of note, different localization of TLR 5 dependent on the anatomical localization (basolateral in bronchi, but apical in alveolar cells) has been observed and seems to parallel the burden of microbial contact. $^{51}$

\section{TRANS-ACTING FACTORS}

Besides the regulation of airway epithelial cells' intrinsic sensitivity towards microbial sensing, pulmonary epithelial cells produce a variety of factors that regulate professional immune cells present in the respiratory microenvironment. Under homeostatic conditions, these cells mainly encompass macrophages, dendritic cells, and lymphocytes. Such factors are found in three functional groups: effects by direct cell-cell contact, local acting cytokines, and lipophilic factors (Figure 1).

\section{Contact-dependent regulation of airway and lung immune reactions}

The reactivity of alveolar AT-I cells towards LPS is markedly increased in the presence of alveolar macrophages. ${ }^{43}$ This effect is most likely mediated by direct cell-cell contacts as conditioned media of alveolar macrophages showed the opposite effect. Interestingly, the presence of AT-II cells decreased TNF $\alpha$ and IL- 6 production of alveolar macrophages upon LPS challenge. This effect could not be seen in mice deficient in CD200. ${ }^{52}$ CD200 is the ligand for CD200R, which is expressed in all myeloid cells. However, the highest levels are found in alveolar macrophages. ${ }^{52,53} \mathrm{CD} 200$-deficient mice or CD200R agonists were able to increase or ameliorate, respectively, influenza-induced pulmonary inflammation, ${ }^{52}$ thus proving an immunosuppressing function of AT-II cells

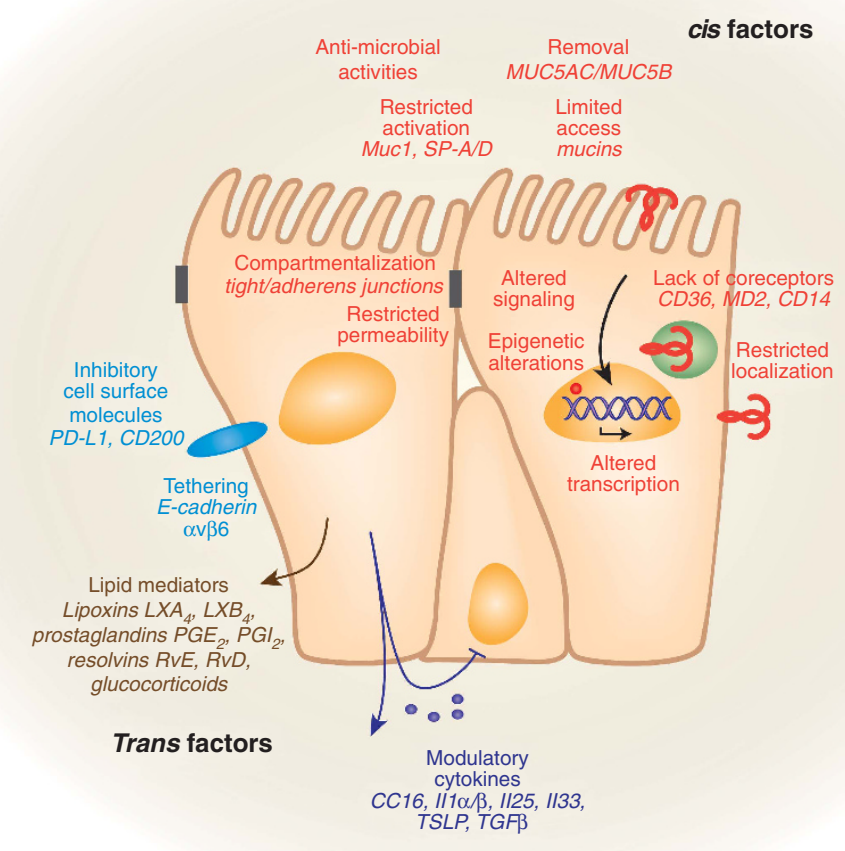

Figure 1 Cis-and trans-acting immune-modulatory factors of airway epithelial cells. Airway epithelial cells limit their sensory potential under homeostatic conditions by cis-acting factors that increase the threshold of activation by luminal microbial stimuli. In addition, airway epithelial cells act on professional cells, inducing a specific microenvironment in trans, by expressing inhibitory cell surface molecules and secretion of modulatory cytokines and lipophilic factors. 
expressing CD200- on CD200R-expressing alveolar macrophages. Moreover, CD200R deficiency protected mice from influenza-induced secondary bacterial superinfection, as influenza is able to induce CD200 expression in the lung. ${ }^{54}$ The anti-inflammatory properties of CD200 have also been addressed for therapeutic usage. It was shown in a rat model of asthma that reduction of infiltrating Th2 lymphocytes and inflammatory dendritic cells could be achieved by intratracheal administration of recombinant CD200. ${ }^{55}$ CD200 is not only expressed by AT-II cells but also in Club cells extending the previous regulatory circuit to the alveolar duct and ciliated bronchiolar epithelium with apically localized CD200. ${ }^{56}$ As myeloid cells can only be found in the subepithelial compartment in the conducting airway, this regulation might be especially important under inflammatory conditions when evaded leukocytes can be observed in the airway lumen.

Another immunomodulatory cell surface protein expressed by pulmonary epithelial cells is PD-L1 ${ }^{57-59} \mathrm{PD}-\mathrm{L} 1$ is known to be expressed by antigen-presenting cells and to mediate T-cell apoptosis, anergy, and functional exhaustion by activating its receptor PD-1. ${ }^{60}$ The functional relevance of a PD-L1/PD-1 interaction between airway epithelial cells and $\mathrm{T}$ cells has been demonstrated in the context of human metapneumovirus. This ligand-receptor pair mediated functional impairment of $\mathrm{CD}^{+}{ }^{+} \mathrm{T}$ cells ${ }^{57,61}$ and increased clearance of influenza. ${ }^{58}$ PD-1 expression has also been shown on dendritic cells ${ }^{62}$ or macrophages ${ }^{61,63}$ and adoptively transferred PD-1-deficient DCs into wild-type mice performed better in clearing bacterial pathogens from the blood stream as compared with wild-type DCs. This effect was independent of the presence of $\mathrm{T}$ and $\mathrm{B}$ cells, arguing for a regulatory function in the innate immune system as well. ${ }^{62}$ This observation also implies a potential interaction between airway epithelial cells and myeloid cells. Indeed, it was shown recently that airway epithelial cells are able to dampen LPS-induced TNF $\alpha$ release in monocytes and macrophages partly dependent on epithelial PD-L1. ${ }^{59}$ In addition, E-cadherin expressed in all airway epithelial cells is able to modulate $\mathrm{CD} 103^{+}$leukocytes, namely intraepithelial dendritic cells and $\mathrm{T}$ cells. ${ }^{64-66} \mathrm{CD} 03^{+}$dendritic cells have been proposed to be important for the induction of $\mathrm{T}_{\text {reg }}$ cells in the intestine; however, a more proinflammatory phenotype of these cells have been described in the lung. ${ }^{67-69}$ However, CD103-deficient mice performed less well in a murine model of asthma. $^{64}$

\section{Epithelial cell-derived modulatory cytokines}

Besides cell-cell contacts, immunomodulatory activities have also been identified in supernatants of epithelial cells. Moreover, molecules mediating cell-matrix interactions such as $\alpha_{\mathrm{V}} \beta_{6}$-integrin have immunomodulatory properties. Integrin $\alpha_{V} \beta_{6}$ binds to the extracellular matrix proteins fibronectin, vitronectin, and tenascin, and the expression is restricted to epithelial cells of the endometrium, lung, and kidney. However, unlike other integrins, expression of integrin $\alpha_{v} \beta_{6}$ can also be induced upon injury or inflammation in various organs. ${ }^{70-73}$ It was shown that mice deficient in integrin $\beta_{6}$ developed airway hyperresponsiveness to acetylcholine, a symptom associated with asthma, had increased infiltration of lymphocytes into the conducting airways, ${ }^{74}$ and displayed age-related emphysema. ${ }^{75}$ Subsequently, it could be shown that epithelial integrin $\alpha_{v} \beta_{6}$ is able to bind and activate latency-associated peptide/tumor growth factor- $\beta$ (TGF $\beta$ ) complexes, thereby locally regulating TGF $\beta$ activity and function. ${ }^{76}$ Mice lacking integrin $\alpha_{\mathrm{V}} \beta_{6}$ were protected against OVA-induced allergic asthma despite increased basal inflammation as TGF $\beta$ activates mast cells. ${ }^{77}$ Moreover, acute lung injury and pulmonary fibrosis was reduced, as TGF $\beta$ is able to modulate epithelial cell permeability $^{78}$ and to induce myofibroblast development, respectively. ${ }^{76,79}$ The local activation of TGF $\beta$ by integrin $\alpha_{V} \beta_{6}$ leads to a high level of TGF $\beta$ in the lung ${ }^{80}$ and it has been demonstrated that TGF $\beta$ inhibits Th1/Th2 differentiation. In line with these results, airway epithelial cell-derived TGF $\beta$ also blocked lymphocyte proliferation. ${ }^{81}$ The context-dependent functions of TGF $\beta$ confirm the central immunomodulatory function of epithelial cells as its local activation is performed by integrin $\alpha_{\mathrm{v}} \beta_{6}$ expressed by epithelial cells.

Another anti-inflammatory and immunomodulatory cytokine with a specific function in the lung is CC16, also known as CCSP or uteroglobulin, and is produced exclusively by club cells. For a long time, serum CC16 levels have been proposed as a prognostic biomarker for COPD. ${ }^{82}$ Initial attempts failed to demonstrate physiological significance of CC16 in cigarette-induced bronchitis and emphysema using CC16-deficient mice. ${ }^{83}$ However, a recent study showed increased susceptibility of CC16-deficient mice to emphysema and peribronchial fibrosis using a long-term cigarette smoke exposing protocol. ${ }^{84}$ CC16 was able to inhibit LPS- or IL-1 $\beta$-mediated nuclear factor- $\kappa \mathrm{B}$ activation in airway epithelial cells ${ }^{85-87}$ and LPS- or IL-13-mediated mucus hypersecretion. ${ }^{87}$ In addition, cigarette smoke induction of IL-8 release was inhibited ${ }^{88}$ and CC16 modulated protein expression of macrophages. However, the significance of this observation is limited.

\section{Airway epithelial cells shape immune response by cytokine secretion}

Besides these anti-inflammatory cytokines, pulmonary epithelial cells are also able to produce proinflammatory or immunomodulatory cytokines to shape a proper immune response. Most of the research carried out so far focused on the development of asthma and mounting of a Th2 skewed inflammation under conditions of immune challenge. ${ }^{89,90}$

In this respect IL-25, IL-33, and TSLP have been heavily investigated and several recent reviews have been discussing the role of these cytokines in detail. ${ }^{89,90}$ IL-25 and TSLP have especially gained interest as potential therapeutic targets, as both cytokines have been associated with asthma in genomewide association studies. ${ }^{91,92}$ All these cytokines are important in recruiting ILC2 cells, which subsequently produce high levels of cytokines (mainly IL-4, IL-13, IL-5) and mediate a Th2-type inflammation. This leads to a promotion of allergic pulmonary inflammation. IL-25, IL-33, and TSLP have also been discussed 
to mediate in situ hematopoiesis, thereby regulating inflammatory Th2 responses. ${ }^{93}$ They were able to induce recruitment of hematopoietic stem/progenitor cells to mucosal surfaces upon inflammation. ${ }^{93-97}$ Of note, differentiating ILCs from hematopoetic stem/progenitor cell is difficult as they share similar cytokine profiles and similar surface markers such as CD90 and CD117. ${ }^{98}$ Therefore, the role of ILC and in situ hematopoiesis in the literature might be misleading and care must be taken in future research to differentiate both mechanisms under pathologic conditions.

IL-33 belongs to the IL-1 superfamily that comprises of IL- $\alpha / \beta$, IL1-Ra, IL-18, IL-33, IL-36 $\alpha / \beta / \gamma$, IL-37, and IL-36Ra and IL-38. IL-1 $\beta$ is a well-known cytokine involved in several inflammatory diseases. IL- $1 \beta$ is regulated at the transcriptional level as well as post-translationally, as the biologically inactive pro-IL- $\beta$ must be activated by the inflammasome. It has been demonstrated that sputum cells from asthmatic patients display lower IL-1 $\beta$ secretion upon LPS stimulation compared with healthy control, ${ }^{99,100}$ and therefore a role of IL- $1 \beta$ in asthma development has been postulated. ${ }^{101}$ However, contradictory observations for mice deficient in IL- $1 \beta$ or deficient in enzymes involved in activation of IL-1 $\beta$ (e.g., caspase-1, Asc, Nlrp3) in murine models of asthma have been described. ${ }^{102-105}$ Mice deficient in IL-1R, the receptor for IL- $1 \alpha / \beta$, have been demonstrated to be protected from house dust mite-induced asthma ${ }^{106}$ and neutrophilic inflammation in a murine model of $\mathrm{CF}{ }^{107}$ Interestingly, both studies suggest a more important role of IL- $1 \alpha$ than IL- $1 \beta$ in these pathologies. Taken together, the ability of epithelial cells to secrete cytokines under inflammatory conditions to shape the immune response in a lungappropriate manner further demonstrates the importance of these cells once hyporesponsiveness is disturbed.

\section{Lipophilic factors regulate homeostatic lung immune reactivity}

Lipoxins. Derivatives of the arachidonic acid (AA), a 20-carbon polyunsaturated fatty acid, including lipoxins (LXs) and prostaglandins (PGs) contribute to lung physiology. Both groups of lipids, also known as eicosanoids, are synthesized by airway epithelial cells and exert their effect on various immune cells. During recent years interactions between different immune cells and airway epithelial cells involving these factors have been shown. LXs are a good example of this crosstalk as the synthesis of LX depends on various cell populations in a kind of transcellular production. LXs $\left(\mathrm{LXA}_{4}, \mathrm{LXB}_{4}\right)$ are anti-inflammatory derivatives of AA and are produced by two enzymes, 15-lipoxygenase, expressed in airway epithelial cells and macrophages, and 5-LO, expressed in eosinophils, neutrophils, monocytes, and macrophages. ${ }^{108}$ Epithelial 15-LO converts AA into 15-hydroxyeicosatetraenoic acid, which is further processed by 5 -LO into $\mathrm{LXA}_{4}$ and $\mathrm{LXB}_{4}$. It has been shown that human airway epithelial cells convert AA predominantly into 15-hydroxyeicosatetraenoic acid and to a much lesser extent into PGs, leukotrienes, or others. ${ }^{109}$ The transcellular synthesis of LX was initially described to occur in the interplay of alveolar macrophages and neutrophils, ${ }^{110}$ but has been subsequently demonstrated for epithelial cells and neutrophils as well. ${ }^{111}$ The principal receptor for $\mathrm{LXA}_{4}$ is ALX/FRP2, ${ }^{112}$ but $\mathrm{LXA}_{4}$ can also trigger other receptors; the specific receptor for $\mathrm{LXB}_{4}$ has not been identified so far. LXs act generally as a "stop signal" during inflammatory reactions ${ }^{108}$ by inhibiting neutrophilic chemotaxis, modulating contraction of pulmonary arteries, and acting as antiphlogistics. LXs are also able to inhibit nuclear factor $-\kappa B$ signaling, thereby inhibiting LPS-mediated proinflammatory cytokine secretion by neutrophils and macrophages. ${ }^{113}$ Moreover, $\mathrm{LXA}_{4}$ modulates transepithelial ion transport and leads to increased airway surface liquid heights. ${ }^{114}$ This is of special importance in the context of $\mathrm{CF}$, where the mutation of cystic fibrosis transmembrane conductance regulator leads to a decrease in airway surface layer height. Moreover, transepithelial ion transport is able to modulate the anti-bacterial effect of the airway mucus. ${ }^{115}$ In addition, $\mathrm{LXA}_{4}$ is able to modulate the repair of the airway epithelium by regulating the proliferation and migration of epithelial cells. ${ }^{116}$

Prostaglandins. AA can also be metabolized by cyclooxygenase (COX) into $\mathrm{PG} \mathrm{H}_{2}\left(\mathrm{PGH}_{2}\right)$. $\mathrm{PGH}_{2}$ can then be converted into the prostanoids $\mathrm{PGD}_{2}, \mathrm{PGE}_{2}, \mathrm{PGF}_{2}$, and $\mathrm{PGI}_{2}$ by their specific synthases, namely PGDS, PGES, PGFS, and PGIS. Two different COX enzymes (COX1, COX2) have been identified so far and are the principal targets for nonsteroidal antiinflammatory drugs. COX1 is considered to be constitutively expressed and important for homeostatic PG synthesis. COX2 expression can be induced under inflammatory conditions by cytokines, such as IL-1, IL-2, and LPS. ${ }^{117}$ However, COX2 seems to be constitutively expressed in human and murine lung epithelial cells. ${ }^{118,119}$ In principle, all prostanoids are detectable in lung but only $\mathrm{PGE}_{2}$ and $\mathrm{PGI}_{2}$ are synthesized by airway epithelial cells. ${ }^{109,120,121} \mathrm{PGE}_{2}$ is the most abundant PG produced by epithelial cells, both airway and alveolar, under homeostatic conditions. ${ }^{109,121}$ Even though $\mathrm{PGE}_{2}$ has been described as a proinflammatory mediator, the importance of $\mathrm{PGE}_{2}$ under homeostatic conditions is to suppress inflammatory processes in the lung. ${ }^{122}$ In line with this inhibitory function, $\mathrm{PGE}_{2}$ concentrations in sputa of asthmatic patients are negatively correlated with the number of infiltrating eosinophils ${ }^{123,124}$ and inhaled $\mathrm{PGE}_{2}$ is beneficial for asthmatic patients. ${ }^{125-128}$ Moreover, epithelial cell-derived $\mathrm{PGE}_{2}$ dampens immunoreactivity of pulmonary dendritic cells by suppressing LPS-induced IL-12 and TNF $\alpha$ secretion and increasing IL-10 secretion in parallel. ${ }^{119,129} \mathrm{PGE}_{2}$ is also able to regulate gap junction communication of airway epithelial cells, and thereby airway surface layer volume. ${ }^{130}$

An important role of alveolar epithelial-derived $\mathrm{PGE}_{2}$ has been demonstrated in the context of pulmonary fibrosis, ${ }^{131}$ as decreased $\mathrm{PGE}_{2}$ levels were detectable in pulmonary fibrotic patients. ${ }^{132,133}$ In this disease, $\mathrm{PGE}_{2}$ seems to counteract TGF $\beta$ to suppress the activation of fibroblasts into myofibroblasts. Effects of $\mathrm{PGE}_{2}$ are mediated by four G-protein-coupled EP receptors (EP1-4). Most of the immunomodulatory and antiinflammatory potential of $\mathrm{PGE}_{2}$ is mediated through EP2 and EP4 receptors. ${ }^{119,120}$ EP2-deficient mice displayed stronger 
bronchoconstriction in several models of allergic airway disease, whereas EP4 mediated the repression of LPS-induced cytokine secretion. ${ }^{119}$

In contrast to the homeostatic levels of $\mathrm{PGE}_{2}$, the levels of $\mathrm{PGI}_{2}$ are markedly increased under inflammatory conditions when $\mathrm{PGI}_{2}$ becomes the major epithelial cell-derived COX product in the lung. $\mathrm{PGI}_{2}$ is produced by PGI synthase and signals through its G-protein-coupled receptor IP (prostacyclin receptor). ${ }^{120}$ Despite the well-known function of $\mathrm{PGI}_{2}$ in the cardiovascular system, it is also able to suppress proinflammatory cytokine secretion and to increase IL-10 production by bone marrowderived dendritic cells. ${ }^{134}$ In line with this anti-inflammatory potential, IP-deficient mice performed less well in bleomycininduced pulmonary fibrosis.

Resolvins. Resolvins are generated from the $\omega$-3-polyunsaturated fatty acids, eicosapentaenoic acid, giving rise to the E-series of resolvins (RvE1/2), and docosahexanoic acid, giving rise to the D-series of resolvins (RvD1-4). Airway epithelial cells from asthma and CF patients have depleted intracellular stores of docosahexanoic acid, which implies dysregulated RvD synthesis. ${ }^{135}$ Similar to LXs, resolvins require a multistep transcellular biosynthesis and are considered to mediate the resolution of inflammatory processes. ${ }^{136}$ The production of RvE1/2 depends on epithelial COX2, which gets acetylated by aspirin, whereas RvD is produced by epithelial 15-LOX and neutrophilic 5-LOX. ${ }^{137}$ RvE1 h0as been shown to promote clearance of bacteria in a murine model of pneumonia. Administration of RvE1 protected mice from experimental allergic asthma and $\mathrm{RvD} 1$ promoted resolution in a murine model of acute lung injury. ${ }^{138}$ A potential molecular mechanism for these observations is Resolvin-mediated nuclear factor$\kappa \mathrm{B}$ inhibition and activation of phosphoinositide 3-kinase or extracellular signal-regulated kinase.

\section{Local production of glucocorticoids}

Glucocorticoids (GCs) are widely used anti-inflammatory drugs used to treat several inflammatory disorders, including pulmonary diseases such as persistent asthma, severe or exacerbated COPD, and chronic eosinophilic pneumonia. ${ }^{139}$ GCs mediate their effects by binding to the GC receptor, which subsequently translocates into the nucleus. GC receptor can either act as a homodimeric transcription factor mediating the induction of several anti-inflammatory genes ${ }^{140,141}$ or can modulate the activity of several other transcription factors, e.g., nuclear factor- $\mathrm{\kappa B}$ or activator protein- $1 .{ }^{142,143}$ Synthesis of GCs occurs in the adrenal gland and serum concentrations are controlled by the adrenocorticotropic hormone. In recent years, nonadrenal tissues have also been identified to produce GCs. This is achieved either by de novo synthesis from cholesterol or by reactivation of inactive GC in a

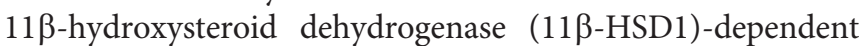
reaction. ${ }^{144}$ Enzymes for the de novo synthesis of GC are expressed during embryonic lung organogenesis. In this context, GCs are important for proper lung development. Indeed, preterm mothers are given high doses of GCs antenatally to prevent respiratory distress syndrome of the neonate. ${ }^{145}$ In line with this, GC receptor deficient mice display severely impaired lung function and die at birth. ${ }^{146} 11 \beta$-HSD 1 is also expressed in the fetal lung, yet seems to be less important for lung development as $11 \beta$-HSD1-deficient mice display a much less severe phenotype. Most likely, the loss of $11 \beta$-HSD1 is compensated by adrenal hyperplasia and increased adrenal GC secretion. ${ }^{147}$ However, expression and GC synthesis by $11 \beta$-HSD1 has recently been reported to take place in adult murine lungs ${ }^{148,149}$ and isolated murine airway epithelial cells. ${ }^{150}$ Interestingly, pulmonary GC synthesis was elevated under inflammatory conditions, indicating a negative feedback mechanism. ${ }^{149}$ Moreover, it was demonstrated that epithelial-derived GC, together with $\mathrm{PGE}_{2}$, are able to induce tolerogenic dendritic cells. ${ }^{119,150}$

\section{SWITCHING EPITHELIAL REGULATION UPON MICROBIAL CHALLENGE: INFLAMMATION IN THE PULMONARY SYSTEM} Given the above-mentioned mediators and modulatory mechanisms, we believe that the default setting in the lung is hyporesponsiveness or tolerance. However, the respiratory immune system has to actively switch to reactivity to allow clearance of pathogens that have established infections after overcoming the initial barriers. This is of special importance as only a few micrometers separate the interior of the body from the environment at the site of gas exchange. Indeed, several studies have demonstrated a proinflammatory role of epithelial cells during inflammation. Therefore, mechanisms must exist to overcome the tolerogenic state of homeostasis and allow epithelial cells to switch from tolerance into a reactive phenotype (Figure 2).

One possible mechanism would be a threshold regulation in which the absolute amount of antigen/PAMP accumulating in the lung is the decisive trigger. Physiologically, the upper respiratory tract filters out larger particles, which are subsequently swallowed and discarded into the gastrointestinal tract. However, smaller particles having an aerodynamic diameter below $2.5-3 \mu \mathrm{m}$ are still able to reach the conducting airways or the lower respiratory tract. ${ }^{37,151}$ These particles might precipitate in the conducting airways, become trapped in the mucus, and are cleared by the MCC. Disturbances of this transport results in chronic inflammatory processes such as $\mathrm{CF}, \mathrm{COPD}$, or ciliary dyskinesia. Similar observations have also been made in several mouse models affecting this process, e.g., Muc5 deficiency, ${ }^{36}$ Scnn $1 \beta$ transgenic mice. ${ }^{152}$ However, smaller particles can also reach the alveolar space. Here, these particles most likely get cleared by phagocytic alveolar macrophages. Yet, because of the steady-state inhibition of PRR signaling, these cells will not mount a strong or systemic immune reaction. However, if the amount of antigens inhaled or accumulated exceeds a potential threshold, this might lead to an activation of macrophages and the secretion of proinflammatory cytokines. Induction of inflammatory cytokines can downregulate inhibitory substances, as has been shown for surfactant, ${ }^{49}$ resulting in a positive feedforward loop that becomes triggered once a certain threshold is overcome. 


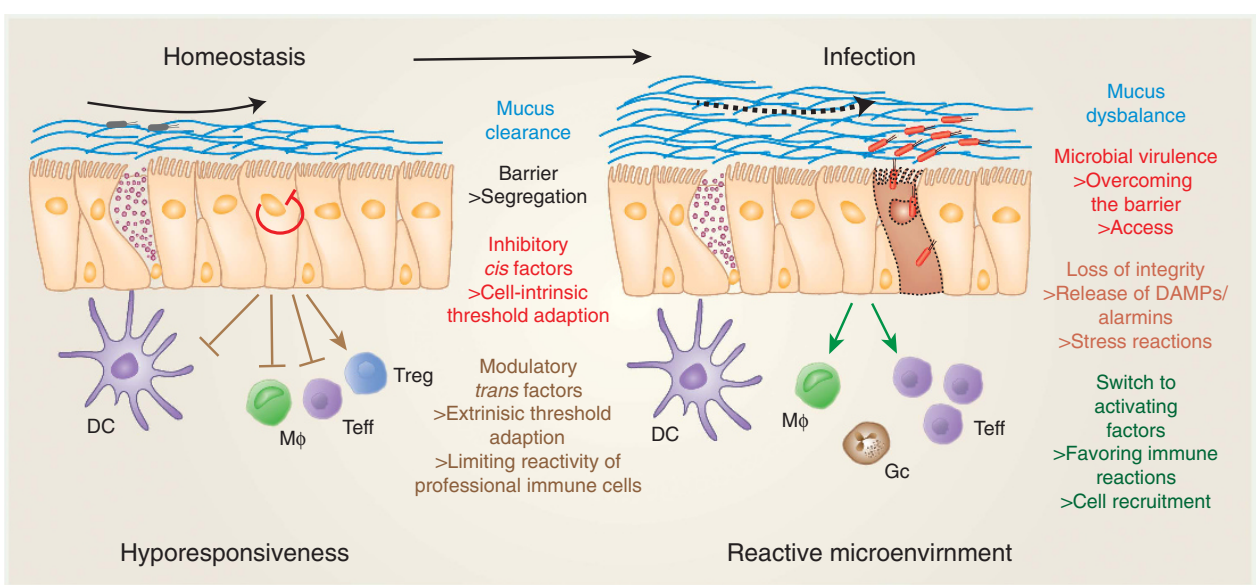

Figure 2 Epithelial cells regulate local immune reactions. Under homeostatic conditions airway epithelial cells promote a tolerogenic microenvironment. This is achieved by regulation of epithelial cells' sensor function in cis as well as the production of modulatory factors acting in trans on professional immune cells. Upon infectious encounter regulatory actions are reduced and proinflammatory activities induced generating a reactive microenvironment. Loss of epithelial cell integrity is a decisive checkpoint in this switching process.

Indeed, a specific role of alveolar macrophages in mounting pulmonary inflammatory processes has previously been proposed. ${ }^{1,153}$ Their phagocytic capacity may be of special importance, whereby antigen uptake by alveolar macrophage would inhibit the transmission of these antigens to pulmonary dendritic cells. ${ }^{154}$ By preventing the activation of dendritic cells, alveolar macrophages would be able to inhibit the activation of the adaptive immune system. ${ }^{1}$

Another mechanism could be based on the type of antigen or PAMP inhaled. It has been shown that airway epithelial cells are able to sense special PAMPs. Whereas airway epithelial cells are generally hyporesponsive towards prototypical PAMPs, including LPS or LTA, they do secrete proinflammatory cytokines upon poly-dI:dC challenge with the secretion of proinflammatory cytokines. This copies the clinical situation of bronchitis, which is usually caused by viruses but not by bacteria, resulting in an increased presence of viral PAMPs. Thus, it is possible that hyporesponsiveness is restricted to certain types of antigens/PAMPs. In this context, the concept of the so-called viability-associated (vita) PAMPs, ${ }^{155}$ microbial molecules that only exist in viable microbes (e.g., bacterial mRNA), is an interesting alternative. Sensing mainly vita-PAMPs would mean that the inhalation of dead bacteria (characterized by a rapid loss of bacterial mRNA) does not elicit inflammation, whereas the presence of viable bacteria would result in activation. Here, specific PAMPs would act to signal infectious danger in a manner similar to vaccine adjuvants.

Another feature of many pulmonary pathogens is that they are able to induce cell death in airway epithelial cells. Therefore, interfering with epithelial cell integrity would, of course, result in lowering the above-mentioned immunomodulatory substances and the physical barrier function. In that case, inflammation would result from microbe-derived virulence factors destroying barrier cells and epithelium integrity, resulting in the release of inhibition. This would allow virulent microbes to reach the subepithelial compartment where they would encounter professional immune cells no longer suppressed by epithelial cell-derived substances. In addition, coordinated MCC needs an intact epithelial lining and disruption by epithelial cell loss might lead to the accumulation of antigen. Moreover, necrotic cell death leads to the release of several alarmins, including IL-33 and IL-1a, ${ }^{106,107}$ both of which have been demonstrated to mount inflammatory responses.

Another cellular response able to induce proinflammatory cytokine secretion in epithelial cells is the unfolded protein response (UPR). UPR is activated upon endoplasmic reticulum stress, which occurs because of the accumulation of unfolded proteins in the endoplasmic lumen. ${ }^{156}$ As chronic activation of UPR can also induce apoptosis, UPR combines several of the above-mentioned mechanism to induce inflammatory processes in the lung. Several agents are known to induce endoplasmic reticulum stress, including cigarette smoke, ${ }^{157}$ bacteria, ${ }^{158}$ and viruses. ${ }^{159}$ Moreover, several chronic inflammatory pulmonary diseases have been linked to ER stress as well, including asthma, pulmonary fibrosis, and cystic fibrosis. ${ }^{160-162}$ Nevertheless, the exact molecular role of UPR signaling under these conditions is still a matter of ongoing research.

\section{CONCLUSIONS}

Taken together, we have discussed evidence that airway epithelial cells are able to suppress inflammatory processes using various mechanisms. These include inhibition of endogenous PRR signaling as well as inhibition of professional leukocytes by cell-cell contacts or secretion of inhibitory substances (cytokines, eicosanoids, and GC). Hyporesponsiveness can be overcome upon infection with pathogens. Epithelial cell integrity will be an important checkpoint in this process, with downregulation of modulatory activities and upregulation of proinflammatory factors once epithelial cells are threatened by microbial infection. Therefore, airway 
epithelial cells are a major player/modulator of airway and lung homeostasis and inflammation. Disturbance of these mechanisms may contribute to various chronic inflammatory diseases.

\section{ACKNOWLEDGMENTS}

This work was supported by a grant of the German Research Foundation (DFG, Collaborative Research Center SFB938/E to AD). We thank Lauren Byrnes for help with preparing the manuscript. We apologize to all colleagues whose work could not be cited owing to space limitations.

\section{DISCLOSURE}

The authors declare no conflict of interest.

(c) 2016 Society for Mucosal Immunology

\section{REFERENCES}

1. Guilliams, M., Lambrecht, B.N. \& Hammad, H. Division of labor between lung dendritic cells and macrophages in the defense against pulmonary infections. Mucosal Immunol. 6, 464-473 (2013).

2. Mayer, A.K. et al. Differential recognition of TLR-dependent microbial ligands in human bronchial epithelial cells. J. Immunol. (Baltimore Md.: 1950) 178, 3134-3142 (2007).

3. Liu, P. et al. Retinoic acid-inducible gene I mediates early antiviral response and Toll-like receptor 3 expression in respiratory syncytial virus-infected airway epithelial cells. J. Virol. 81, 1401-1411 (2007).

4. Gavino, A.C.P., Chung, J.-S., Sato, K., Ariizumi, K. \& Cruz, P.D. Identification and expression profiling of a human C-type lectin, structurally homologous to mouse dectin-2. Exp. Dermatol. 14, 281-288 (2005).

5. Heyl, K.A. et al. Dectin-1 is expressed in human lung and mediates the proinflammatory immune response to nontypeable Haemophilus influenzae. mBio 5, e01492-e01414 (2014).

6. Hirota, J.A. et al. The airway epithelium nucleotide-binding domain and leucine-rich repeat protein 3 inflammasome is activated by urban particulate matter. J. Allergy Clin. Immunol. 129, 1116-1125 (2012).

7. Kummer, J.A. et al. Inflammasome components NALP 1 and 3 show distinct but separate expression profiles in human tissues suggesting a site-specific role in the inflammatory response. J. Histochem. Cytochem. Off. J. Histochem. Soc. 55, 443-452 (2007).

8. Slevogt, H. et al. Moraxella catarrhalis is internalized in respiratory epithelial cells by a trigger-like mechanism and initiates a TLR2- and partly NOD1-dependent inflammatory immune response. Cell. Microbiol. 9, 694-707 (2007).

9. Sun, L., Wu, J., Du, F., Chen, X. \& Chen, Z.J. Cyclic GMP-AMP synthase is a cytosolic DNA sensor that activates the type I interferon pathway. Science 339, 786-791 (2013).

10. Baral, P., Batra, S., Zemans, R.L., Downey, G.P. \& Jeyaseelan, S. Divergent functions of Toll-like receptors during bacterial lung infections. Am. J. Respir. Crit. Care Med. 190, 722-732 (2014).

11. Poltorak, A. et al. Defective LPS signaling in $\mathrm{C} 3 \mathrm{H} / \mathrm{HeJ}$ and C57BL/10ScCr mice: mutations in Tlr4 gene. Science 282, 2085-2088 (1998).

12. Qureshi, S.T. et al. Endotoxin-tolerant mice have mutations in Toll-like receptor 4 (TIr4). J. Exp. Med. 189, 615-625 (1999).

13. Raz, E. Organ-specific regulation of innate immunity. Nat. Immunol. 8, 3-4 (2007).

14. Guilliams, M. et al. Alveolar macrophages develop from fetal monocytes that differentiate into long-lived cells in the first week of life via GM-CSF. J. Exp. Med. 210, 1977-1992 (2013).

15. Happle, C. etal. Pulmonary transplantation of macrophage progenitors as effective and long-lasting therapy for hereditary pulmonary alveolar proteinosis. Sci. Transl. Med. 6, 250ra113 (2014).

16. Johansson, M.E.V. et al. The inner of the two Muc2 mucin-dependent mucus layers in colon is devoid of bacteria. Proc. Natl. Acad. Sci. USA 105, 15064-15069 (2008).

17. Johansson, M.E.V., Sjövall, H. \& Hansson, G.C. The gastrointestinal mucus system in health and disease. Nat. Rev. Gastroenterol. Hepatol. 10, 352-361 (2013).
18. Cario, E. Microbiota and innate immunity in intestinal inflammation and neoplasia. Curr. Opin. Gastroenterol. 29, 85-91 (2013).

19. Brune, K., Frank, J., Schwingshackl, A., Finigan, J. \& Sidhaye, V.K. Pulmonary epithelial barrier function: some new players and mechanisms. Am. J. Physiol. Lung Cell. Mol. Physiol 308, L731-L745 (2015).

20. Jahnsen, F.L. et al. Accelerated antigen sampling and transport by airway mucosal dendritic cells following inhalation of a bacterial stimulus. J. Immunol. 177, 5861-5867 (2006).

21. Veres, T.Z. et al. Spatiotemporal and functional behavior of airway dendritic cells visualized by two-photon microscopy. Am. J. Pathol. 179, 603-609 (2011).

22. Thornton, E.E. et al. Spatiotemporally separated antigen uptake by alveolar dendritic cells and airway presentation to Tcells in the lung. J. Exp. Med. 209, 1183-1199 (2012).

23. Wiener-Kronish, J.P., Albertine, K.H. \& Matthay, M.A. Differential responses of the endothelial and epithelial barriers of the lung in sheep to Escherichia coli endotoxin. J. Clin. Invest. 88, 864-875 (1991).

24. Bachofen, M. \& Weibel, E.R. Alterations of the gas exchange apparatus in adult respiratory insufficiency associated with septicemia. Am. Rev. Respir. Dis. 116, 589-615 (1977).

25. Xiao, C. et al. Defective epithelial barrier function in asthma. J. Allergy Clin. Immunol. 128, 549-556 (2011).

26. de Boer, W.I. et al. Altered expression of epithelial junctional proteins in atopic asthma: possible role in inflammation. Can. J. Physiol. Pharmacol. 86, 105-112 (2008).

27. Kim, K.C. Role of epithelial mucins during airway infection. Pulm. Pharmacol. Ther. 25, 415-419 (2012).

28. Evans, C.M. et al. Mucin is produced by clara cells in the proximal airways of antigen-challenged mice. Am. J. Respir. Cell Mol. Biol. 31, 382-394 (2004).

29. Jarrard, J.A. et al. MUC1 is a novel marker for the type II pneumocyte lineage during lung carcinogenesis. Cancer Res. 58, 5582-5589 (1998).

30. Tilley, A.E., Walters, M.S., Shaykhiev, R. \& Crystal, R.G. Cilia dysfunction in lung disease. Annu. Rev. Physiol. 77, 379-406 (2015).

31. Sheehan, J.K., Kesimer, M. \& Pickles, R. Innate immunity and mucus structure and function. Novartis Found. Symp. 279, 155-166 (2006). discussion 167-169, 216-219.

32. Zhen, G. et al. IL-13 and epidermal growth factor receptor have critical but distinct roles in epithelial cell mucin production. Am. J. Respir. Cell Mol. Biol. 36, 244-253 (2007).

33. Young, H.W.J. et al. Central role of Muc5ac expression in mucous metaplasia and its regulation by conserved $5^{\prime}$ elements. Am. J. Respir. Cell Mol. Biol. 37, 273-290 (2007).

34. Hasnain, S.Z. et al. Muc5ac: a critical component mediating the rejection of enteric nematodes. J. Exp. Med. 208, 893-900 (2011).

35. Koeppen, M. et al. Detrimental role of the airway mucin Muc5ac during ventilator-induced lung injury. Mucosal Immunol. 6, 762-775 (2013).

36. Roy, M.G. et al. Muc5b is required for airway defence. Nature 505 , 412-416 (2014).

37. Raabe, O.G., Al-Bayati, M.A., Teague, S.V. \& Rasolt, A. Regional deposition of inhaled monodisperse coarse and fine aerosol particles in small laboratory animals. Ann. Occup. Hyg. 32, 53-63 (1988).

38. Lu, W. et al. Cutting edge: enhanced pulmonary clearance of Pseudomonas aeruginosa by Muc1 knockout mice. J. Immunol. (Baltimore Md.: 1950) 176, 3890-3894 (2006).

39. Ueno, K. et al. MUC1 mucin is a negative regulator of Toll-like receptor signaling. Am. J. Respir. Cell Mol. Biol. 38, 263-268 (2008).

40. Ioannidis, I., Ye, F., McNally, B., Willette, M. \& Flaño, E. Toll-like receptor expression and induction of type I and type III interferons in primary airway epithelial cells. J. Virol. 87, 3261-3270 (2013).

41. Becker, M.N., Diamond, G., Verghese, M.W. \& Randell, S.H. CD14dependent lipopolysaccharide-induced beta-defensin-2 expression in human tracheobronchial epithelium. J. Biol. Chem. 275, 29731-29736 (2000).

42. Jia, H.P. et al. Endotoxin responsiveness of human airway epithelia is limited by low expression of MD-2. Am. J. Physiol. Lung Cell. Mol. Physiol 287, L428-L437 (2004).

43. Wong, M.H. \& Johnson, M.D. Differential response of primary alveolar type I and type II cells to LPS stimulation. PLoS One 8, e55545 (2013). 
44. Neagos, J. et al. Epigenetic regulation of tolerance to TLR ligands in alveolar epithelial cells. Am. J. Respir. Cell Mol. Biol.; doi:10.1165/ rcmb.2015-00570C (2015).

45. Murakami, S. et al. Surfactant protein A inhibits peptidoglycan-induced tumor necrosis factor-alpha secretion in U937 cells and alveolar macrophages by direct interaction with toll-like receptor 2. J. Biol. Chem. 277, 6830-6837 (2002).

46. Sato, M. et al. Direct binding of Toll-like receptor 2 to zymosan, and zymosan-induced NF-kappa B activation and TNF-alpha secretion are down-regulated by lung collectin surfactant protein A. J. Immunol. (Baltimore, Md: 1950) 171, 417-425 (2003).

47. Yamada, C. et al. Surfactant protein A directly interacts with TLR4 and MD-2 and regulates inflammatory cellular response. Importance of supratrimeric oligomerization. J. Biol. Chem. 281, 21771-21780 (2006).

48. Ohya, M. et al. Human pulmonary surfactant protein $D$ binds the extracellular domains of Toll-like receptors 2 and 4 through the carbohydrate recognition domain by a mechanism different from its binding to phosphatidylinositol and lipopolysaccharide. Biochemistry (Mosc.) 45, 8657-8664 (2006).

49. Väyrynen, O., Glumoff, V. \& Hallman, M. Regulation of surfactant proteins by LPS and proinflammatory cytokines in fetal and newborn lung. Am. J. Physiol. 282, L803-L810 (2002).

50. Muir, A. et al. Toll-like receptors in normal and cystic fibrosis airway epithelial cells. Am. J. Respir. Cell Mol. Biol. 30, 777-783 (2004).

51. Shikhagaie, M.M. et al. Mapping of TLR5 and TLR7 in central and distal human airways and identification of reduced TLR expression in severe asthma. Clin. Exp. Allergy J. Br. Soc. Allergy Clin. Immunol. 44, 184-196 (2014).

52. Snelgrove, R.J. et al. A critical function for CD200 in lung immune homeostasis and the severity of influenza infection. Nat. Immunol. 9, 1074-1083 (2008).

53. Gwyer Findlay, E. \& Hussell, T. Macrophage-mediated inflammation and disease: a focus on the lung. Mediators Inflamm. 2012, 140937 (2012).

54. Goulding, J. et al. Lowering the threshold of lung innate immune cell activation alters susceptibility to secondary bacterial superinfection. J. Infect. Dis. 204, 1086-1094 (2011).

55. Lauzon-Joset, J.-F. et al. Lung CD200R activation abrogates airway hyperresponsiveness in experimental asthma. Am. J. Respir. Cell Mol. Biol. 53, 276-284 (2015).

56. Jiang-Shieh, Y.-F. et al. Distribution and expression of CD200 in the rat respiratory system under normal and endotoxin-induced pathological conditions. J. Anat. 216, 407-416 (2010).

57. Stanciu, L.A. et al. Expression of programmed death-1 ligand (PD-L) 1, PD-L2, B7-H3, and inducible costimulator ligand on human respiratory tract epithelial cells and regulation by respiratory syncytial virus and type 1 and 2 cytokines. J. Infect. Dis. 193, 404-412 (2006).

58. McNally, B., Ye, F., Willette, M. \& Flaño, E. Local blockade of epithelial PDL-1 in the airways enhances T cell function and viral clearance during influenza virus infection. J. Virol. 87, 12916-12924 (2013).

59. Oumouna, M. et al. Cell-contact dependent inhibition of monocytes by airway epithelial cells and reversion by infection with rRespiratory syncytial virus. Immunobiology 220, 1240-1245 (2005).

60. Shi, L., Chen, S., Yang, L. \& Li, Y. The role of PD-1 and PD-L1 in T-cell immune suppression in patients with hematological malignancies. J. Hematol. Oncol. 6, 74 (2013).

61. Erickson, J.J. et al. Viral acute lower respiratory infections impair CD8 + T cells through PD-1. J. Clin. Invest. 122, 2967-2982 (2012).

62. Yao, S. et al. PD-1 on dendritic cells impedes innate immunity against bacterial infection. Blood 113, 5811-5818 (2009).

63. Huang, X. et al. PD-1 expression by macrophages plays a pathologic role in altering microbial clearance and the innate inflammatory response to sepsis. Proc. Natl. Acad. Sci. USA 106, 6303-6308 (2009).

64. Bernatchez, E. et al. Pulmonary CD103 expression regulates airway inflammation in asthma. Am. J. Physiol. Lung Cell. Mol. Physiol. 308, L816-L826 (2015).

65. GeurtsvanKessel, C.H. \& Lambrecht, B.N. Division of labor between dendritic cell subsets of the lung. Mucosal Immunol. 1, 442-450 (2008).

66. Sung, S.-S. J. et al. A major lung CD103 (alphaE)-beta7 integrin-positive epithelial dendritic cell population expressing Langerin and tight junction proteins. J. Immunol. 176, 2161-2172 (2006).
67. Nakano, H. et al. Pulmonary CD103(+) dendritic cells prime Th2 responses to inhaled allergens. Mucosal Immunol. 5, 53-65 (2012).

68. Desch, A.N. et al. CD103+ pulmonary dendritic cells preferentially acquire and present apoptotic cell-associated antigen. J. Exp. Med. 208, 1789-1797 (2011)

69. Semmrich, M. et al. Directed antigen targeting in vivo identifies a role for CD103(+) dendritic cells in both tolerogenic and immunogenic T-cell responses. Mucosal Immunol. 208, 1789-1797 (2011).

70. Breuss, J.M., Gillett, N., Lu, L., Sheppard, D. \& Pytela, R. Restricted distribution of integrin beta 6 mRNA in primate epithelial tissues. J. Histochem. Cytochem. Off. J. Histochem. Soc. 41, 1521-1527 (1993).

71. Busk, M., Pytela, R. \& Sheppard, D. Characterization of the integrin alpha $\checkmark$ beta 6 as a fibronectin-binding protein. J. Biol. Chem. 267, 5790-5796 (1992).

72. Weinacker, A. et al. Role of the integrin alpha v beta 6 in cell attachment to fibronectin. Heterologous expression of intact and secreted forms of the receptor. J. Biol. Chem. 269, 6940-6948 (1994).

73. Prieto, A.L., Edelman, G.M. \& Crossin, K.L. Multiple integrins mediate cell attachment to cytotactin/tenascin. Proc. Natl. Acad. Sci. USA 90, 10154-10158 (1993).

74. Huang, X.Z. et al. Inactivation of the integrin beta 6 subunit gene reveals a role of epithelial integrins in regulating inflammation in the lung and skin. J. Cell Biol. 133, 921-928 (1996).

75. Morris, D.G. et al. Loss of integrin alpha(v)beta6-mediated TGF-beta activation causes Mmp12-dependent emphysema. Nature 422, 169-173 (2003).

76. Munger, J.S. et al. The integrin alpha $v$ beta 6 binds and activates latent TGF beta 1: a mechanism for regulating pulmonary inflammation and fibrosis. Cell 96, 319-328 (1999).

77. Sugimoto, K. et al. The $\alpha_{v} \beta_{6}$ integrin modulates airway hyperresponsiveness in mice by regulating intraepithelial mast cells. J. Clin. Invest. 122, 748-758 (2012).

78. Pittet, J.F. et al. TGF-beta is a critical mediator of acute lung injury. J. Clin. Invest. 107, 1537-1544 (2001).

79. Horan, G.S. et al. Partial inhibition of integrin alpha(v)beta6 prevents pulmonary fibrosis without exacerbating inflammation. Am. J. Respir. Crit. Care Med. 177, 56-65 (2008).

80. Mayer, A.K. \& Dalpke, A.H. Regulation of local immunity by airway epithelial cells. Arch. Immunol. Ther. Exp. (Warsz.) 55, 353-362 (2007).

81. Mayer, A.K., Bartz, H., Fey, F., Schmidt, L.M. \& Dalpke, A.H. Airway epithelial cells modify immune responses by inducing an anti-inflammatory microenvironment. Eur. J. Immunol. 38, 1689-1699 (2008).

82. Bernard, A., Marchandise, F.X., Depelchin, S., Lauwerys, R. \& Sibille, Y. Clara cell protein in serum and bronchoalveolar lavage. Eur. Respir. J. 5, 1231-1238 (1992).

83. Park, H.Y. et al. Club cell protein 16 and disease progression in chronic obstructive pulmonary disease. Am. J. Respir. Crit. Care Med. 188, 1413-1419 (2013).

84. Laucho-Contreras, M.E. et al. Protective role for club cell secretory protein-16 (CC16) in the development of COPD. Eur. Respir. J. 45, 1544-1556 (2015)

85. Long, X.-B. et al. Clara cell 10-kDa protein gene transfection inhibits NF- $\kappa B$ activity in airway epithelial cells. PLoS One 7, e35960 (2012).

86. Hiemstra, P.S. \& Bourdin, A. Club cells, CC10 and self-control at the epithelial surface. Eur. Respir. J. 44, 831-832 (2014).

87. Tokita, E., Tanabe, T., Asano, K., Suzaki, H. \& Rubin, B.K. Club cell 10-kDa protein attenuates airway mucus hypersecretion and inflammation. Eur. Respir. J. 44, 1002-1010 (2014).

88. Gamez, A.S. et al. Supplementing defect in club cell secretory protein attenuates airway inflammation in COPD. Chest 147, 1467-1476 (2015).

89. Hallstrand, T.S. et al. Airway epithelial regulation of pulmonary immune homeostasis and inflammation. Clin. Immunol. (Orlando, FL) 151, 1-15 (2014).

90. Lloyd, C.M. \& Saglani, S. Epithelial cytokines and pulmonary allergic inflammation. Curr. Opin. Immunol. 34, 52-58 (2015).

91. Moffatt, M.F. et al. A large-scale, consortium-based genomewide association study of asthma. N. Engl. J. Med. 363, 1211-1221 (2010).

92. Hunninghake, G.M. et al. TSLP polymorphisms are associated with asthma in a sex-specific fashion. Allergy 65, 1566-1575 (2010). 
93. Hui, C.C.K., McNagny, K.M., Denburg, J.A. \& Siracusa, M.C. In situ hematopoiesis: a regulator of TH2 cytokine-mediated immunity and inflammation at mucosal surfaces. Mucosal Immunol. 8, 701-711 (2015).

94. Allakhverdi, Z. et al. CD34 + hemopoietic progenitor cells are potent effectors of allergic inflammation. J. Allergy Clin. Immunol. 123, 472-478 (2009).

95. Saenz, S.A. et al. IL25 elicits a multipotent progenitor cell population that promotes $T(H) 2$ cytokine responses. Nature 464, 1362-1366 (2010).

96. Allakhverdi, Z. et al. Mast cell-activated bone marrow mesenchymal stromal cells regulate proliferation and lineage commitment of CD34(+) progenitor cells. Front. Immunol. 4, 461 (2013).

97. Siracusa, M.C. et al. Thymic stromal lymphopoietin-mediated extramedullary hematopoiesis promotes allergic inflammation. Immunity 39 , 1158-1170 (2013).

98. Spits, H. et al. Innate lymphoid cells-a proposal for uniform nomenclature. Nat. Rev. Immunol. 13, 145-149 (2013).

99. Hernandez, M.L. et al. Atopic asthmatic patients have reduced airway inflammatory cell recruitment after inhaled endotoxin challenge compared with healthy volunteers. J. Allergy Clin. Immunol. 130, 869-876 (2012).

100. Brickey, W.J. et al. Sputum inflammatory cells from patients with allergic rhinitis and asthma have decreased inflammasome gene expression. J. Allergy Clin. Immunol. 128, 900-903 (2011).

101. dos Santos, G., Kutuzov, M.A. \& Ridge, K.M. The inflammasome in lung diseases. Am. J. Physiol. Lung Cell. Mol. Physiol. 303, L627-L633 (2012).

102. Besnard, A.-G. et al. NLRP3 inflammasome is required in murine asthma in the absence of aluminum adjuvant: role of NLRP3 inflammasome in murine asthma. Allergy 66, 1047-1057 (2011).

103. Allen, I.C. et al. Analysis of NLRP3 in the development of allergic airway disease in mice. J. Immunol. (Baltimore, Md.: 1950) 188, 2884-2893 (2012).

104. Hirota, J.A. et al. The nucleotide-binding domain, leucine-rich repeat protein 3 inflammasome/L-1 receptor I axis mediates innate, but not adaptive, immune responses after exposure to particulate matter under 10 um. Am. J. Respir. Cell Mol. Biol. 52, 96-105 (2015).

105. Eisenbarth, S.C., Colegio, O.R., O'Connor, W., Sutterwala, F.S. \& Flavell, R.A. Crucial role for the Nalp3 inflammasome in the immunostimulatory properties of aluminium adjuvants. Nature 453, 1122-1126 (2008).

106. Willart, M.A.M. et al. Interleukin- $1 \alpha$ controls allergic sensitization to inhaled house dust mite via the epithelial release of GM-CSF and IL-33. J. Exp. Med. 209, 1505-1517 (2012).

107. Fritzsching, B. et al. Hypoxic epithelial necrosis triggers neutrophilic inflammation via IL-1 receptor signaling in cystic fibrosis lung disease. Am. J. Respir. Crit. Care Med. 191, 902-913 (2015).

108. Bäck, M. et al. Update on leukotriene, lipoxin and oxoeicosanoid receptors: IUPHAR Review 7. Br. J. Pharmacol. 171, 3551-3574 (2014).

109. Holtzman, M.J., Hansbrough, J.R., Rosen, G.D. \& Turk, J. Uptake, release and novel species-dependent oxygenation of arachidonic acid in human and animal airway epithelial cells. Biochim. Biophys. Acta 963, 401-413 (1988).

110. Levy, B.D. etal. Human alveolar macrophages have 15-lipoxygenase and generate 15(S)-hydroxy-5,8,11-cis-13-trans-eicosatetraenoic acid and lipoxins. J. Clin. Invest. 92, 1572-1579 (1993).

111. Clària, J., Lee, M.H. \& Serhan, C.N. Aspirin-triggered lipoxins (15-epi-LX) are generated by the human lung adenocarcinoma cell line (A549)neutrophil interactions and are potent inhibitors of cell proliferation. Mol. Med. (Cambridge, MA) 2, 583-596 (1996).

112. Fiore, S., Maddox, J.F., Perez, H.D. \& Serhan, C.N. Identification of a human CDNA encoding a functional high affinity lipoxin A4 receptor. J. Exp. Med. 180, 253-260 (1994).

113. Urbach, V., Higgins, G., Buchanan, P. \& Ringholz, F. The role of lipoxin A4 in cystic fibrosis lung disease. Comput. Struct. Biotechnol. J. 6, e201303018 (2013).

114. Verrière, V. etal. Lipoxin A4 stimulates calcium-activated chloride currents and increases airway surface liquid height in normal and cystic fibrosis airway epithelia. PLoS One 7, e37746 (2012).

115. Verkman, A.S., Song, Y. \& Thiagarajah, J.R. Role of airway surface liquid and submucosal glands in cystic fibrosis lung disease. Am. J. Physiol. 284, C2-C15 (2003).

116. Buchanan, P.J., McNally, P., Harvey, B.J. \& Urbach, V. Lipoxin $A_{4}-$ mediated KATP potassium channel activation results in cystic fibrosis airway epithelial repair. Am. J. Physiol. Lung Cell. Mol. Physiol. 305, L193-L201 (2013).

117. Kang, Y.-J., Mbonye, U.R., DeLong, C.J., Wada, M. \& Smith, W.L. Regulation of intracellular cyclooxygenase levels by gene transcription and protein degradation. Prog. Lipid Res. 46, 108-125 (2007).

118. Soslow, R.A. et al. COX-2 is expressed in human pulmonary, colonic, and mammary tumors. Cancer 89, 2637-2645 (2000).

119. Schmidt, L.M. et al. Bronchial epithelial cell-derived prostaglandin E2 dampens the reactivity of dendritic cells. J. Immunol. (Baltimore Md.: 1950) 186, 2095-2105 (2011).

120. Claar, D., Hartert, T.V. \& Peebles, R.S. The role of prostaglandins in allergic lung inflammation and asthma. Expert Rev. Respir. Med. 9, 55-72 (2014).

121. Churchill, L. et al. Cyclooxygenase metabolism of endogenous arachidonic acid by cultured human tracheal epithelial cells. Am. Rev. Respir. Dis. 140, 449-459 (1989).

122. Nakanishi, M. \& Rosenberg, D.W. Multifaceted roles of PGE2 in inflammation and cancer. Semin. Immunopathol. 35, 123-137 (2013).

123. Aggarwal, S., Moodley, Y.P., Thompson, P.J. \& Misso, N.L. Prostaglandin E2 and cysteinyl leukotriene concentrations in sputum: association with asthma severity and eosinophilic inflammation. Clin. Exp. Allergy J. Br. Soc. Allergy Clin. Immunol. 40, 85-93 (2010).

124. Pavord, I.D. et al. Induced sputum eicosanoid concentrations in asthma. Am. J. Respir. Crit. Care Med. 160, 1905-1909 (1999).

125. Gauvreau, G.M., Watson, R.M. \& O'Byrne, P.M. Protective effects of inhaled PGE2 on allergen-induced airway responses and airway inflammation. Am. J. Respir. Crit. Care Med. 159, 31-36 (1999).

126. Pavord, I.D., Wong, C.S., Williams, J. \& Tattersfield, A.E. Effect of inhaled prostaglandin E2 on allergen-induced asthma. Am. Rev. Respir. Dis. 148, 87-90 (1993).

127. Melillo, E., Woolley, K.L., Manning, P.J., Watson, R.M. \& O'Byrne, P.M. Effect of inhaled PGE2 on exercise-induced bronchoconstriction in asthmatic subjects. Am. J. Respir. Crit. Care Med. 149, 1138-1141 (1994).

128. Pavord, I.D. \& Tattersfield, A.E. Bronchoprotective role for endogenous prostaglandin E2. Lancet Lond. Engl. 345, 436-438 (1995).

129. Kaliński, P., Hilkens, C.M., Snijders, A., Snijdewint, F.G. \& Kapsenberg, M.L. IL-12-deficient dendritic cells, generated in the presence of prostaglandin E2, promote type 2 cytokine production in maturing human naive T helper cells. J. Immunol. 159, 28-35 (1997).

130. Scheckenbach, K.E.L. et al. Prostaglandin $\mathrm{E}_{2}$ regulation of cystic fibrosis transmembrane conductance regulator activity and airway surface liquid volume requires gap junctional communication. Am. J. Respir. Cell Mol. Biol. 44, 74-82 (2011).

131. Bozyk, P.D. \& Moore, B.B. Prostaglandin E2 and the pathogenesis of pulmonary fibrosis. Am. J. Respir. Cell Mol. Biol. 45, 445-452 (2011).

132. Ozaki, T. et al. Regulatory effect of prostaglandin E2 on fibronectin release from human alveolar macrophages. Am. Rev. Respir. Dis. 141, 965-969 (1990).

133. Borok, Z. et al. Augmentation of functional prostaglandin E levels on the respiratory epithelial surface by aerosol administration of prostaglandin $\mathrm{E}$. Am. Rev. Respir. Dis. 144, 1080-1084 (1991).

134. Müller, T. et al. lloprost has potent anti-inflammatory properties on human monocyte-derived dendritic cells. Clin. Exp. Allergy J. Br. Soc. Allergy Clin. Immunol. 40, 1214-1221 (2010).

135. Roulet, M., Frascarolo, P., Rappaz, I. \& Pilet, M. Essential fatty acid deficiency in well nourished young cystic fibrosis patients. Eur. J. Pediatr. 156, 952-956 (1997).

136. Serhan, C.N. Pro-resolving lipid mediators are leads for resolution physiology. Nature 510, 92-101 (2014).

137. Uddin, M. \& Levy, B.D. Resolvins: natural agonists for resolution of pulmonary inflammation. Prog. Lipid Res. 50, 75-88 (2011).

138. Eickmeier, O. et al. Aspirin-triggered resolvin D1 reduces mucosal inflammation and promotes resolution in a murine model of acute lung injury. Mucosal Immunol. 6, 256-266 (2013).

139. Rhen, T. \& Cidlowski, J.A. Antiinflammatory action of glucocorticoidsnew mechanisms for old drugs. N. Engl. J. Med. 353, 1711-1723 (2005).

140. Frijters, R. et al. Prednisolone-induced differential gene expression in mouse liver carrying wild type or a dimerization-defective glucocorticoid receptor. BMC Genomics 11, 359 (2010). 
141. Reichardt, H.M. et al. DNA binding of the glucocorticoid receptor is not essential for survival. Cell 93, 531-541 (1998).

142. Heck, S. et al. A distinct modulating domain in glucocorticoid receptor monomers in the repression of activity of the transcription factor AP-1. EMBO J 13, 4087-4095 (1994).

143. Caldenhoven, E. et al. Negative cross-talk between RelA and the glucocorticoid receptor: a possible mechanism for the antiinflammatory action of glucocorticoids. Mol. Endocrinol. (Baltimore, Md.) 9, 401-412 (1995).

144. Agarwal, A.K., Monder, C., Eckstein, B. \& White, P.C. Cloning and expression of rat cDNA encoding corticosteroid 11 beta-dehydrogenase. J. Biol. Chem. 264, 18939-18943 (1989).

145. Liggins, G.C. \& Howie, R.N. A controlled trial of antepartum glucocorticoid treatment for prevention of the respiratory distress syndrome in premature infants. Pediatrics 50, 515-525 (1972).

146. Cole, T.J. et al. Targeted disruption of the glucocorticoid receptor gene blocks adrenergic chromaffin cell development and severely retards lung maturation. Genes Dev. 9, 1608-1621 (1995).

147. Kotelevtsev, Y. et al. 11beta-hydroxysteroid dehydrogenase type 1 knockout mice show attenuated glucocorticoid-inducible responses and resist hyperglycemia on obesity or stress. Proc. Natl. Acad. Sci. USA 94, 14924-14929 (1997).

148. Kostadinova, F., Schwaderer, J., Sebeo, V. \& Brunner, T. Why does the gut synthesize glucocorticoids? Ann. Med. 46, 490-497 (2014).

149. Hostettler, N. et al. Local glucocorticoid production in the mouse lung is induced by immune cell stimulation. Allergy 67, 227-234 (2012).

150. Weitnauer, M. et al. Bronchial epithelial cells induce alternatively activated dendritic cells dependent on glucocorticoid receptor signaling. J. Immunol. (Baltimore Md.: 1950) 193, 1475-1484 (2014).

151. Corrin, B. \& Nicholson, A.G In: Pathology of the Lungs, 2nd (edn) (Nicholson, B.C.G., ed.) 327-399 (Churchill Livingstone; 2011). available at: http://www.sciencedirect.com/science/article/pii/B978070 2033698000070.

152. Mall, M., Grubb, B.R., Harkema, J.R., O’Neal, W.K. \& Boucher, R.C. Increased airway epithelial $\mathrm{Na}+$ absorption produces cystic fibrosis-like lung disease in mice. Nat. Med. 10, 487-493 (2004).

153. Lambrecht, B.N. Alveolar macrophage in the driver's seat. Immunity $\mathbf{2 4}$ 366-368 (2006).

154. MacLean, J.A. et al. Sequestration of inhaled particulate antigens by lung phagocytes. A mechanism for the effective inhibition of pulmonary cell-mediated immunity. Am. J. Pathol. 148, 657-666 (1996).

155. Mourao-Sa, D., Roy, S. \& Blander, J.M. Vita-PAMPs: signatures of microbial viability. Adv. Exp. Med. Biol. 785, 1-8 (2013).

156. Oakes, S.A. \& Papa, F.R. The role of endoplasmic reticulum stress in human pathology. Annu. Rev. Pathol. 10, 173-194 (2015).

157. Kelsen, S.G. et al. Cigarette smoke induces an unfolded protein response in the human lung. Am. J. Respir. Cell Mol. Biol. 38, 541-550 (2008).

158. Celli, J. \& Tsolis, R.M. Bacteria, the endoplasmic reticulum and the unfolded protein response: friends or foes? Nat. Rev. Microbiol. 13, 71-82 (2015).

159. Fung, T.S., Torres, J. \& Liu, D.X. The emerging roles of viroporins in er stress response and autophagy induction during virus infection. Viruses 7 , 2834-2857 (2015).

160. Korfei, M. et al. Epithelial endoplasmic reticulum stress and apoptosis in sporadic idiopathic pulmonary fibrosis. Am. J. Respir. Crit. Care Med. 178, 838-846 (2008).

161. Bartoszewski, R. et al. Activation of the unfolded protein response by deltaF508 CFTR. Am. J. Respir. Cell Mol. Biol. 39, 448-457 (2008).

162. Kim, S.R. et al. Endoplasmic reticulum stress influences bronchial asthma pathogenesis by modulating nuclear factor $\mathrm{\kappa B}$ activation. J. Allergy Clin. Immunol. 132, 1397-1408 (2013). 